\title{
Construction of decision rules for early detection of a developing concrete arch dam failure scenario. A discriminant approach
}

\author{
J. Mata ${ }^{a}, *$, N. Schclar Leitão ${ }^{a}$, A. Tavares de Castro ${ }^{a}$, J. Sá da Costa ${ }^{b}$ \\ ${ }^{a}$ Concrete Dams Department, National Laboratory for Civil Engineering, Av. do Brasil 101, 1700-066 Lisbon, Portugal \\ ${ }^{\mathrm{b}}$ IST, University of Lisbon, Av. Rovisco Pais 1, 1049-001 Lisbon, Portugal
}

\section{A R T I C L E I N F O}

\section{Article history:}

Received 18 February 2013

Accepted 9 July 2014

\section{Keywords:}

Concrete dams

Discriminant models

Dam failure scenarios

Safety control

Real time monitoring

\begin{abstract}
A B S T R A C T
To improve the effectiveness of concrete dam safety control in real time, a method is presented for the construction of decision rules for the early detection of developing failure scenarios. The decision rules are based on the use of linear discriminant models developed with data obtained through mathematical models of the dam's behaviour. The aim is to combine the physical quantities measured by the automated monitoring system of the dam, appropriately weighted, into a new single index allowing the classification of the observations into one of two classes (normal behaviour and development of a failure scenario).
\end{abstract}

(c) 2014 Elsevier Ltd. All rights reserved.

\section{Introduction}

The major potential modes of failure of concrete dams are related to natural phenomena such as a flood, rockslide, earthquake, and the deterioration of the heterogeneous foundations and construction materials [1].

Dam safety control activities require an accurate knowledge of each specific dam, with the purpose of defining and justifying the judgment about its safety. This task is mainly supported by cross validation between simulation models, measurements provided by the monitoring systems, and the parameters that characterise the dam's behaviour. The main issue is the assessment of the actual structural behaviour in real conditions, which can be used to detect any anomaly and/or malfunction in advance. The symptoms are not always timely detected in a concrete dam failure situation, leading to an uncontrolled progressive evolution of the problem until the verification of an accident or even the dam's rupture.

There are historical cases where abnormal dam behaviour was monitored before dam failure without successfully triggering alert to evaluate the population at risk, such as the cases of the Malpasset dam in 1959 [2,3] and the Vajont dam in 1963 [4,5].

Over the years, the evolution in the process of interpreting the physical quantities provided by dam monitoring systems is significant. Nowadays, Automated Monitoring Systems (AMS) have

\footnotetext{
* Corresponding author. Tel.: +351 218443372; fax: +351 218443026 .

E-mail addresses: jmata@lnec.pt (J. Mata), nschclar@lnec.pt (N. Schclar Leitão), tcastro@lnec.pt (A. Tavares de Castro), sadacosta@dem.ist.utl.pt (J. Sá da Costa).
}

become a reality in several dams. These systems can be used to support the analysis for dam safety assessment in real time, but also lead to the increase of requirements related to the management, processing and analysis of large amounts of data. The development of internal early warning systems based on the automatic analysis of a large quantity of data in real time allows the possibility of early identification and notification of potential abnormal situations. However, the detection of abnormal behaviour in AMS is usually achieved through the assessment of each physical quantity in an independent manner, it not being possible to infer about the global dam behaviour. Thus, the next step is to implement decision rules that allow for the assessment of a group of physical quantities in order to detect early if the global dam behaviour is normal or in accordance with a developing failure scenario. In this context, dam behaviour is considered normal if it satisfies the following requirements: structural dam safety is verified, and the observed dam behaviour is in accordance with the expected dam behaviour based on mathematical or physical models, and past measurements under the same main loads (if available). Mathematical models are those most commonly used in the safety control of concrete dams. Within these type of models, two fundamental methods are usually used to predict a dependent variable (behaviour indicator) from other independent variables: the deterministic and the statistical methods. In addition to these two methods, there is another method, the hybrid method, resulting from the combination of the first two methods [6]. In deterministic methods, rheological laws of material are used (e.g. Finite Element or Discrete Element methods), and in statistical models, multiple linear 